\title{
Design Across the Curriculum: Reinforcing the Design Process in a Chemistry-for-Engineers Course
}

\section{Prof. Katherine Goodman, University of Colorado Denver}

Katherine Goodman is assistant professor at the University of Colorado Denver, and curriculum lead at Inworks, an interdisciplinary innovation lab. Her research focuses on transformative experiences in engineering education. She is currently division chair of the Technological and Engineering Literacy Philosophy of Engineering Division (TELPhE).

\section{Ms. Susan Garver Stirrup, University of Colorado Denver}

Susan Garver Stirrup is a full time Instructor in the College of Engineering, Design, and Computing at the University of Colorado Denver. Her primary focus is developing and delivering the Chemistry For Engineers course, tailoring the chemistry content for engineering majors. Susan earned her MS in Chemistry from The University of Michigan. 


\title{
Design Across the Curriculum: Reinforcing the Design Process in a Chemistry-for-Engineers Course
}

\begin{abstract}
At the University of Colorado Denver, the engineering college has had a long-standing first-year course covering general chemistry from an engineering perspective, taught by the College of Engineering since 2017. In the past three years, this course has been re-designed to have projectbased components, highlighting the engineering uses of chemistry, such as using chemistry knowledge to evaluate material properties for an engineering application. Alongside more traditional chemistry exams, students complete a set of smaller individual projects and a semester-long team-based design challenge. In the design challenge they use the design process to develop a solution to an environmental or health issue of their choosing. While completing the individual projects, students apply their chemistry knowledge to engineering situations. The team design challenge incorporates the same engineering design process as used in the first year engineering design course, which many students take concurrently. Prior to Spring 2020, this course had a lively in-person format. In the transition to remote learning necessitated by the pandemic starting in Spring 2020, the instructor was able to convert the course more deliberately for a Fall 2020 delivery. Now the course is offered in a fully online, synchronous fashion. Here we discuss both student reaction to the course over time as the design process became more explicitly scaffolded and future plans for studying the incorporation of design across the curriculum.
\end{abstract}

\section{Introduction}

This work-in-progress paper shares the redesign of a chemistry-for-engineers course to include more opportunities for learning the design process.

Engineers grapple with ill-structured problems that have multiple solutions [1]. Therefore, providing opportunities early and throughout an engineering student's education to practice design is essential. Many engineering programs now require first year design experiences, as well as senior capstone projects. Between those early and late design courses, there can be a "desert of design" -- many dense analytical courses with few structured opportunities for teambased design work. Institutions that manage to build in design across the curriculum have been highlighted as groundbreaking (e.g. [2]). To avoid the problem of encapsulation, or only seeing what they learn as relevant within a specific course [3], it is important to provide students a variety of contexts where they can apply their design skills. Notice, too, that the problem of encapsulation also impacts learning other content, such as chemistry. Therefore the motivation for this work was twofold: the instructor re-designed assignments to utilize chemistry knowledge with engineering skills, which gives students additional experiences utilizing a design process and also practice drawing new chemistry knowledge into that process. As Dym et al. point out, design "know how" includes being able to use a "synthesis of knowledge from many disciplines" [4]. 


\section{Context of the Course}

At the University of Colorado Denver, leadership of the College of Engineering is shifting its emphasis toward design and computing across the curriculum, with a goal of better preparing engineers for future challenges. These changes have included broad signals, with a name change from the College of Engineering and Applied Science to the College of Engineering, Design, and Computing, as well as detailed efforts, such as redesigning individual courses to provide more active learning experiences that use a design process. As part of this effort, the College has reorganized the first-year design course offerings, which were formerly customized to the individual departments, into a common course shared by all departments, as of Fall 2020. Similarly, the changes to the chemistry course described here were motivated by these goals. The College has a long-standing history of teaching this one semester chemistry course. It is a five-credit course that covers the content generally covered in a full year of chemistry (General Chemistry I and II). Rather than a lab, this course has two recitation sections per week that primarily focus on problem solving. Prior to 2016, the course was taught by the chemistry department in the College of Liberal Arts and Sciences. The course then transitioned to the College of Engineering, taught there for the first time in Spring 2017. The current instructor began teaching the course in Fall 2017, and significant changes have been made as she continues to iterate on the delivery methods.

\section{Class Iterations}

During Fall 2017 and Spring 2018 the course was taught in a fairly traditional manner, with quiz and exam scores making up a large part of the final grade (75\%). A group project, the Environmental Challenge, was also required, constituting $15 \%$ of the overall grade in the course. Students, in groups of three to four, chose an environmental challenge that exists worldwide, then developed and presented their solution to that challenge. The students were given a little bit of class time, but most work was done outside of class. The instructor provided a basic process of how to approach the challenge, but teams were not given intermediate deadlines or a design process to scaffold their work. Teams were required to create a visual representation of their design, which might be 3D renderings, diagrams, models, or other prototypes of their solution. The challenge culminated in a presentation to their peers and a panel of experts, consisting of engineering professors and leadership, and industry professionals from the engineering and scientific community in the Denver area.

As part of the College's renewed focus on design and computing, the instructor altered the course significantly for the Fall 2018 - Spring 2019 academic year. Since the course is required for all Mechanical, Civil, and Electrical Engineering majors early on in their academic program, redesigning this one course was hoped to be a leverage point to shift students' perspectives. The instructor converted the Environmental Challenge into the Environmental Design Challenge, following the Stanford d.school model for the design process [5]. The students were given class time to discuss and work through the design process (empathize, define, ideate, prototype, test). The instructor explained each mode and worked with the students in their design teams to help them understand the modes and create robust solutions. Students received feedback from "users" during informal conversation with one other design group and again during a small group presentation to three to four other groups. The culminating activity was a poster session in which students displayed their work and college faculty and staff were invited to attend. Students were required to have a physical prototype to display and interact with during the poster session. The 
Design Challenge increased to $20 \%$ of the students' overall grade and quizzes and exams decreased to $60 \%$.

Table 1: Changes to the course design of Chemistry for Engineers, with numbers of students and survey response rates

\begin{tabular}{|c|c|c|c|c|}
\hline Iteration & First & Second & Third & Fourth \\
\hline Term & F17 / S18 & F18/S19 & F19/S20 & F20/S21 \\
\hline $\begin{array}{c}\text { Grade } \\
\text { emphasis }\end{array}$ & $\begin{array}{c}\text { Quizzes 15\% } \\
\text { Recitation 5\% } \\
\text { Teamwork 5\% } \\
\text { Group Project } \\
15 \%\end{array}$ & $\begin{array}{c}\text { Exams 60\% } \\
\text { Recitation 20\% } \\
\text { Design Challenge } \\
20 \%\end{array}$ & $\begin{array}{c}\text { Exams + Quizzes } \\
55 \% \\
\text { Recitation 20\% } \\
\text { Design Challenge } \\
25 \%\end{array}$ & $\begin{array}{c}\text { Quizzes 10\% } \\
\text { Recitation 10\% } \\
\text { Design Challenge } \\
\text { 25\% } \\
\text { Individual Projects } \\
25 \%\end{array}$ \\
\hline $\begin{array}{c}\text { Design } \\
\text { Process }\end{array}$ & none & $\begin{array}{c}\text { Stanford d.school } \\
\text { "5 hexagons" }\end{array}$ & $\begin{array}{c}\text { Design Innovation } \\
\text { "4Ds" }\end{array}$ & $\begin{array}{c}\text { Design Innovation } \\
\text { "4Ds" }\end{array}$ \\
\hline Enrollment & 192 & 199 & 171 & 72 (fall only) \\
\hline $\begin{array}{c}\text { Survey } \\
\text { Responses }\end{array}$ & 172 & 174 & 154 & 65 (fall only) \\
\hline $\begin{array}{c}\text { Survey } \\
\text { Response } \\
\text { Rate }\end{array}$ & $89.6 \%$ & $87.4 \%$ & $90.1 \%$ & $90.3 \%$ \\
\hline
\end{tabular}

Minor course changes were made for the Fall 2019 - Spring 2020 academic year. The college adopted the 4D Design Innovation Method [6], so the instructor changed the language of the project to reflect that terminology and process (discover, define, develop, deliver). The Environmental Design Challenge remained largely unchanged in terms of expectations and culminating activities. The Design Challenge increased to $25 \%$ of the overall grade and quizzes and exams fell to 55\%. See Table 1 for summary of course elements and changes over time.

As with most universities, the pandemic closures of Spring 2020 required modifications to the course. Following a campus-wide closure in March, the course remained the same as originally planned, but some key things became evident to the instructor. First, exam security was an issue. The heavy reliance on traditional high-stakes assessments (i.e. exams) is stressful to students, and it became clear that these assessments did not clearly gage student knowledge. Given that the instructor had already been weighing options for alternative methods of assessment for a few semesters, the pandemic hastened the move to implement project-based learning and active learning into the course for Fall 2020.

For the Fall 2020 semester, the instructor developed five individual projects that incorporated $25 \%$ of the overall grade. The Design Challenge remained at $25 \%$, but the exam / quiz category decreased to $35 \%$ of the overall grade. The main goals of the projects are:

1. Give the students practice on calculations / concepts covered in class

2. Relate chemistry principles to engineering applications

3. Introduce / Develop engineering vocabulary and how to think about engineering issues involving chemistry 
4. Opportunity to practice design principles with open-ended questions.

To evaluate the effectiveness of various elements of the course, a course survey was conducted.

\section{Methods}

The effectiveness of these changes is being assessed using student responses to a survey, administered after the team Design Challenge is completed. This survey is presented as quiz in the learning management system, and has a high response rate, $n=565$ out of 634 students enrolled, or more than $89 \%$. This assignment is graded on completion for a very small portion of the overall Design Challenge grade. It is presented to the students as an opportunity to reflect on their Design Challenge experiences. See Table 1 for responses by iteration of the course. The questions have remained constant for all 16 sections during the seven semesters of results presented. For this preliminary work, we focused on the open-response question, "What is the most important thing you learned in this project?" Using a priori codes for Teamwork/ Collaboration and Design Process, all 565 responses were coded. Some responses were labeled with more than one code, and some responses did not align with either code. See Table 2 for representative examples of student responses coded for each of these responses.

Table 2: Qualitative codes used with sample of student responses

\begin{tabular}{|l|l|}
\hline Code & Representative Responses \\
\hline Teamwork/ Collaboration & $\begin{array}{l}\text { "Teamwork! Helping each other and working } \\
\text { together in every step" } \\
\text { "I learned how to work in a group and respect } \\
\text { others ideas." } \\
\text { “...the importance of listening to other } \\
\text { peoples ideas. }\end{array}$ \\
\hline Design Process & $\begin{array}{l}\text { “...enjoyed going through the stages of } \\
\text { design and putting them into action." } \\
\text { "I learned that there's more to designing a } \\
\text { product than just doing what is convenient.... } \\
\text { "I learned to have empathy in my designs. } \\
\text { This made me aware of how the user is the } \\
\text { most important part of the process in terms of } \\
\text { design and satisfaction with the design." }\end{array}$ \\
\hline
\end{tabular}

\section{Preliminary Results}

As Table 3 and Figure 1 show, the comments about the design process jumped with the addition of explicit scaffolding for that process. 
Table 3: Student responses by code, by iteration of the course

\begin{tabular}{|c|c|c|c|c|c|c|}
\hline $\begin{array}{c}\text { Iteration of } \\
\text { the course }\end{array}$ & $\begin{array}{c}\text { Academic } \\
\text { Year }\end{array}$ & Design & Teamwork & $\begin{array}{c}\text { Number of } \\
\text { Respondents }\end{array}$ & $\begin{array}{c}\% \text { of Respondents } \\
\text { (Design) }\end{array}$ & $\begin{array}{c}\% \text { of } \\
\text { Respondents } \\
\text { (Teamwork) }\end{array}$ \\
\hline First & F17-S18 & 7 & 60 & 172 & $4.1 \%$ & $34.9 \%$ \\
\hline Second & F18-S19 & 42 & 65 & 174 & $24.1 \%$ & $37.4 \%$ \\
\hline Third & F19-S20 & 41 & 75 & 154 & $26.6 \%$ & $48.7 \%$ \\
\hline Fourth & F20 only & 17 & 34 & 65 & $26.2 \%$ & $52.3 \%$ \\
\hline
\end{tabular}

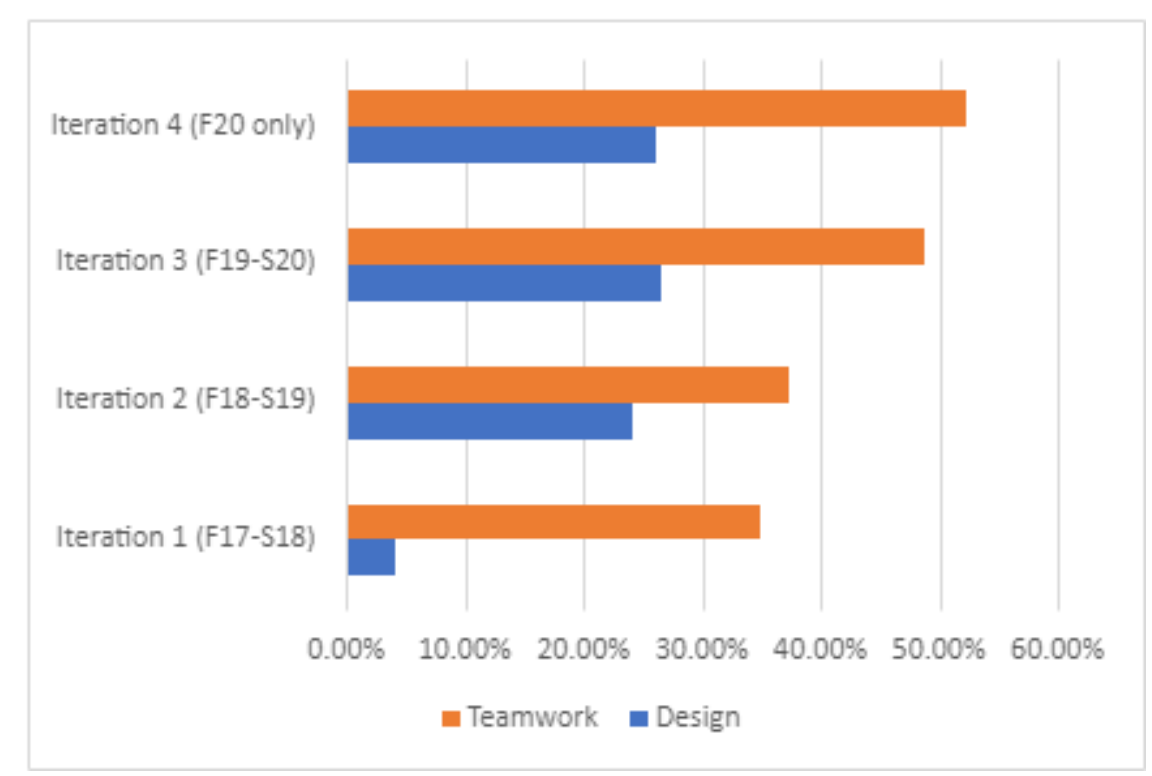

Figure 1: Student responses, coded for Teamwork and Design oriented comments. Deliberate instruction on the design process was started in Fall 2018, Iteration 2.

As a very early study of student experience in the course, we can see that adding the design process to the team Environmental Design Challenge altered what aspect of the project was deemed "most important" to the students. While gaining teamwork or collaboration skills still ranked high, mentions of how to define a problem, the importance of developing more than one solution or prototype, as well as comments on the design process overall, start to become more common.

\section{Future Curricular Work}

While the current instruction for the Environmental Design Challenge will be kept with minor modifications, the instructor would like to continue to iterate on the individual module projects in a few ways. First, as pandemic restrictions lessen, the instructor would like to include additional hands-on pieces to the projects, such as giving the students metal strips to measure on their own, demonstrating reactions, and measuring battery potentials. Second, the students would also benefit from more design-elements being incorporated in the individual projects. These modifications based on feedback from upper-level engineering course professors will also be evaluated and potentially implemented. 
There are also plans to work across the curriculum with other instructors to provide design opportunities in other courses.

\section{Discussion, Limitations, and Future Research}

During this initial study of student responses, we also found emergent topics that may be worth coding and studying further. This includes what are sometimes called transformative experiences, or those moments when students are able to deeply connect their academic work with "real world" experiences [7], such as might be read into these student responses:

"Team Work, Researching, and Chemistry applications to solve real life problems."

and

"I learned more about problems that people face in my own community."

This present study is limited in part by the necessities of the pandemic. First, there was reduced access to students, and classroom observations were not an option. Also, given the number of surveys currently being deployed by the university, we elected to not add to the burden already being placed on students and instead continued to use the current survey, which only covered the team design challenge, and did not ask about the individual projects, added in Iteration 4. Finally, we, the researcher and the instructor, have had our time severely limited by the additional demands of working in remote and limited hybrid mode.

We are in the early stages of implementing our research plan. In addition to further coding of survey data already collected, we would like to include new longitudinal elements particular to this course. In particular, we would like to investigate the following:

1. Do the individual projects help students in their upper-level engineering classes, such as thermodynamics or strength of materials?

2. Do student exhibit improved retention or usage of chemistry knowledge or skills in relevant upper-level courses?

3. Given that students are now also taking a common first-year engineering design course, does having multiple early design experiences contribute to improved senior capstone projects?

Further, it is hoped that giving these students an engineering lens while learning chemistry will contribute to their development of engineering identities and sense of belonging within the College. Future work will include surveys and interview work around identity and belonging, from influences in this course and accompanying initiatives throughout the college.

\section{Conclusion}

Our humble hypothesis is that a wide variety of engineering content learning could be enhanced by providing assignments that use the design process. In this case, we have changed a chemistryfor-engineers course to include both a team design challenge as well as multiple, open-ended individual projects, to provide active learning experiences that include examples of how general chemistry knowledge is used in different engineering applications.

This initial investigation provides nothing conclusive. However, the changes in students' responses on the design challenge survey suggest that students value these design experiences, and recognize the importance of design in their learning and future work. We will continue to 
code the data and survey the students. We would like to investigate whether students were more likely to see the relevance of chemistry knowledge in their engineering work after completing the individual projects in addition to the design challenge.

More broadly, we will continue to study the impacts of redesigning course elements, both in this course and in others, as our College continues its initiative to incorporate design and computing across the curriculum.

\section{References}

[1] K. Goodman and S. T. Frezza, "Finding Möjligheter: Creativity and ill-structured problems," presented at the ASEE Annual Conference and Exposition, Columbus, OH, Jun. 2017, doi: 10.18260/1-2--28358.

[2] M. Somerville et al., "The Olin curriculum: thinking toward the future," IEEE Transactions on Education, vol. 48, no. 1, pp. 198-205, Feb. 2005, doi: 10.1109/TE.2004.842905.

[3] Y. Engeström, "Non Scolae Sed Vitae Discimus: Toward Overcoming the Encapsulation of School Learning," Learning and Instruction, vol. 1, pp. 243-259, 1991.

[4] C. L. Dym, A. M. Agogino, O. Eris, D. D. Frey, and L. J. Leifer, "Engineering Design Thinking, Teaching, and Learning," Journal of Engineering Education, vol. 94, no. January, pp. 103-120, 2005, doi: 10.1002/j.2168-9830.2005.tb00832.x.

[5] D.school, "Design Thinking Bootleg," 2018, [Online]. Available: https://dschool.stanford.edu/resources/design-thinking-bootleg.

[6] B. A. Camburn et al., "Design Innovation: A Study of Integrated Practice," presented at the ASME 2017 International Design Engineering Technical Conferences and Computers and Information in Engineering Conference, Nov. 2017, doi: 10.1115/DETC2017-68382.

[7] K. Goodman, "The Transformative Experience in Engineering Education," University of Colorado, Boulder, CO, 2015. 